ARTICLE

\title{
Oxytocin attenuates phencyclidine hyperactivity and increases social interaction and nucleus accumben dopamine
} release in rats

\author{
Shivali Kohli ${ }^{1}$, Madeleine V. King ${ }^{1}$, Stuart Williams ${ }^{1}$, Adele Edwards ${ }^{1}$, Theresa M. Ballard ${ }^{2}$, Lucinda J. Steward ${ }^{2}$, \\ Daniella Alberati ${ }^{2}$ and Kevin C. F. Fone ${ }^{1}$
}

The pituitary neuropeptide oxytocin promotes social behavior, and is a potential adjunct therapy for social deficits in schizophrenia and autism. Oxytocin may mediate pro-social effects by modulating monoamine release in limbic and cortical areas, which was investigated herein using in vivo microdialysis, after establishing a dose that did not produce accompanying sedative or thermoregulatory effects that could concomitantly influence behavior. The effects of oxytocin (0.03-0.3 mg/kg subcutaneous) on locomotor activity, core body temperature, and social behavior (social interaction and ultrasonic vocalizations) were examined in adult male Lister-hooded rats, using selective antagonists to determine the role of oxytocin and vasopressin $\mathrm{V}_{1 \mathrm{a}}$ receptors. Dopamine and serotonin efflux in the prefrontal cortex and nucleus accumbens of conscious rats were assessed using microdialysis. $0.3 \mathrm{mg} / \mathrm{kg}$ oxytocin modestly reduced activity and caused hypothermia but only the latter was attenuated by the $\mathrm{V}_{1 \mathrm{a}}$ receptor antagonist, SR49059 (1 mg/kg intraperitoneal). Oxytocin at $0.1 \mathrm{mg} / \mathrm{kg}$, which did not alter activity and had little effect on temperature, significantly attenuated phencyclidine-induced hyperactivity and increased social interaction between unfamiliar rats without altering the number or pattern of ultrasonic vocalizations. In the same rats, oxytocin $(0.1 \mathrm{mg} / \mathrm{kg})$ selectively elevated dopamine overflow in the nucleus accumbens, but not prefrontal cortex, without influencing serotonin efflux. Systemic oxytocin administration attenuated phencyclidine-induced hyperactivity and increased pro-social behavior without decreasing core body temperature and selectively enhanced nucleus accumbens dopamine release, consistent with activation of mesocorticolimbic circuits regulating associative/reward behavior being involved. This highlights the therapeutic potential of oxytocin to treat social behavioral deficits seen in psychiatric disorders such as schizophrenia.

Neuropsychopharmacology (2019) 44:295-305; https://doi.org/10.1038/s41386-018-0171-0

\section{INTRODUCTION}

The cross-species-conserved neuropeptide oxytocin is synthesized in the paraventricular and supraoptic nuclei of the hypothalamus [1] and acts via central and peripheral oxytocin and vasopressin $\mathrm{V}_{1 \mathrm{a}}$ and $\mathrm{V}_{1 \mathrm{~b}}$ receptors, as well as renal $\mathrm{V}_{2}$ receptors $[2,3]$. In addition to established roles in lactation and parturition, oxytocin is a key regulator of social and affective behavior $[4,5]$. Accumulating evidence implicates its dysregulation in several neuropsychiatric disorders [6], and oxytocin has received considerable recent interest as a potential adjunct therapy for the social deficits in schizophrenia [7, 8].

Pro-social effects of oxytocin occur across species on multiple facets of interaction, enabling mechanistic studies in rodents. Acute intracerebral administration increases rat maternal behavior [9] and contributes to partner preference in monogamous prairie voles [10], whereas chronic administration suppresses aggression [11] and attenuates stress-induced behavior, cardiac, and autonomic changes in rodents [12]. The oxytocin-induced decrease in $40 \mathrm{kHz}$ "distress" calls by maternally separated rat pups [13] was reversed by an oxytocin antagonist, suggesting involvement of this receptor. However, there are no reports of the effect of oxytocin on rat $50 \mathrm{kHz}$ ultrasonic vocalizations (USVs) accompanying positive emotional states specific to reward-associated situations, which may have translational relevance to communicative deficits associated with negative symptoms in man [14-17].

The N-Methyl-D-aspartic acid (NMDA) receptor antagonist phencyclidine (PCP) can produce "schizophrenia-like" psychotic behavior and cognitive impairments in normal healthy individuals, and reversal of acute PCP-induced hyperactivity in rodents (associated with enhanced prefrontal cortex (PFC) and nucleus accumbens (NAc) dopamine and serotonin (5-HT) release) has been widely used to assess potential antipsychotic drug activity [18-21]. The effect of oxytocin on PCP-induced hyperactivity, as performed herein, has not been reported before.

The formation and maintenance of social bonds in mammals is thought to involve oxytocin-dopamine interactions in the mesocorticolimbic system $[22,23]$ and reinforcement of social reward requires oxytocinergic enhancement of dorsal raphe serotonergic input to the NAC [24]. Infusions of oxytocin into the ventral tegmental area (VTA) of Long Evans rats selected for high grooming behavior, increased NAc dopamine release during bouts

\footnotetext{
${ }^{1}$ School of Life Sciences, University of Nottingham, Queen's Medical Centre, Nottingham NG7 2UH, UK and ${ }^{2}$ F. Hoffmann-La Roche AG, Roche Innovation Centre Basel, Neuroscience Discovery NORD, Grenzacherstrasse 124, Basel CH4070, Switzerland

Correspondence: Kevin C. F. Fone (kevin.fone@nottingham.ac.uk)
}

Received: 27 February 2018 Revised: 20 July 2018 Accepted: 25 July 2018

Published online: 7 August 2018 
of pup grooming, which was attenuated by VTA-infusion of an oxytocin receptor antagonist [25]. The localization of oxytocin receptors to brain regions associated with reward, including the VTA, NAc, and prelimbic cortex, suggest that bond formation and social attachments may have rewarding properties $[2,26,27]$. In addition, partner preference in female prairie voles is differentially influenced by dopamine receptor subtype activation; $D_{1}$ receptors inhibit, whereas $D_{2}$ receptors facilitate partner preference [28-30]. Furthermore, micro-infusion of oxytocin increased NAc dopamine overflow [31] consistent with the proposed involvement of dopamine/oxytocin interaction on social behavior, although the downstream mechanisms involved are unclear. Therefore, we also determined the impact of oxytocin on PFC and NAc dopamine and serotonin $(5-\mathrm{HT})$ release by microdialysis to evaluate their potential role in mediating the pro-social effects observed.

The blood-brain barrier (BBB) penetration of oxytocin is extremely low. A fundamental unresolved controversy limiting any translational therapeutic potential [5] is whether changes in central nervous system (CNS) function can be achieved via systemic administration of the neuropeptide [32] without concomitant adverse peripheral effects, and the mechanisms underlying such CNS effects are yet to be elucidated. The variable effects of oxytocin in preclinical paradigms evaluating positive, negative, and cognitive symptoms of schizophrenia [33] may also be due to confounding activation of other receptors such as the $\mathrm{V}_{1 \mathrm{a}}$. The doses required for "desired" and side-effects of oxytocin are species and gender specific, perhaps reflecting species variation in receptor distribution and sexual dimorphism in innervation $[2,34]$, and may also vary by rat strain. As there are no published effects of oxytocin in Lister-hooded rats, initial dose-response studies established a dose that did not induce hypothermia or hypolocomotion and used oxytocin and $v_{1 a}$ receptor antagonists to elucidated the receptor(s) responsible for these unwanted peripheral effects before determining the effect of oxytocin on PCP-induced hyperactivity, social interaction, USVs, and monoamine release by microdialysis.

\section{MATERIALS AND METHODS}

Animals

Fifty-six male Lister-hooded rats (150-200 g; Charles River UK) were housed in groups of four in ventilated cages or, following surgery for microdialysis, in individual cages. Rats were maintained in a controlled environment $\left(21 \pm 2^{\circ} \mathrm{C}\right.$ and $55 \pm 10 \%$ humidity) on a $12 \mathrm{~h}$ light-dark cycle (lights on 06:00 h) with food and water ad libitum. All experiments were performed in the light phase, and procedures conducted in accordance with the Animals (Scientific Procedures) Act, 1986, the ARRIVE guidelines [35] and approval of the University of Nottingham Local Ethical Committee. Group sizes were selected on the basis of our previous publications using these behavioral [36] and microdialysis techniques [37].

\section{Drugs}

Oxytocin acetate was purchased from Bachem (Saint Helens, UK), the oxytocin antagonist L-368,899 hydrochloride ((2 S)-2-Amino-N[(1 S,2 S,4 R)-7,7-dimethyl-1-[[[4-(2-methylphenyl)-1-piperazinyl] sulfonyl]methyl]bicyclo[2.2.1] hept-2-yl]-4-(methylsulfonyl)butanamide) from Tocris (Bristol, UK), PCP and the $V_{1 a}$ receptor antagonist SR49059 ((2 S)-1-[[(2 R,3 S)-5-Chloro-3-(2-chlorophenyl)-1-[(3,4-dimethoxyphenyl)sulfonyl]-2,3-dihydro-3-hydroxy-1 Hindol-2-yl]carbonyl]-2-pyrrolidinecarboxamide) relcovaptan from Sigma Aldrich (Poole, UK). All compounds were dissolved in $0.154 \mathrm{M}$ saline (vehicle also containing $5 \%$ dimethyl sulfoxide for the antagonists) and administered at volume of $1 \mathrm{ml} / \mathrm{kg}$ subcutaneous (s.c.) (oxytocin) or $2 \mathrm{ml} / \mathrm{kg}$ intraperitoneal (i.p.) (all other compounds). Doses are expressed as the salt. In all cases, the experimenter was unaware of the treatment received both during administration and observation.
Dose-response and antagonist studies with oxytocin on core body temperature and locomotor activity

To establish a suitable dose of oxytocin, which would not suppress locomotor activity (LMA) or produce hypothermia during microdialysis studies, rats $(n=12)$ were tested using a within-subjects design on four occasions at weekly intervals following injection of vehicle and each dose of oxytocin $(0.03,0.1$, or $0.3 \mathrm{mg} / \mathrm{kg}$ s.c.) in a pseudo-random order to serve as their own control. This range was selected from previous reports showing that oxytocin doses above $0.3 \mathrm{mg} / \mathrm{kg}$ s.c. or i.p. suppress spontaneous locomotion in other rat strains [38-40] so we included lower doses to identify those devoid of this unwanted effect. To establish the relative contribution of oxytocin and vasopressin $V_{1 a}$ receptors to hypothermia produced by the highest dose, a further 12 rats received vehicle or oxytocin ( $0.3 \mathrm{mg} / \mathrm{kg}$ s.c.) in the presence and absence of the non-peptide selective $V_{1 a}$ receptor antagonist SR49059 (1 mg/kg i.p.) or the selective oxytocin antagonist L368,899 ( $2 \mathrm{mg} / \mathrm{kg}$ i.p.), on six occasions at weekly intervals (withinsubjects design). Although original peptide antagonists for these receptors showed poor stability and selectivity the development of non-peptide antagonists greatly improved pharmacokinetic properties [41]. The current non-peptide antagonists (SR49059 and $L-368,889$ ) were selected because they possess the best overall profile of commercially available oxytocin and $V_{1 a}$ antagonists; having high affinity, relative selectivity, good BBB penetration, and plasma half-life [41] and are devoid of partial agonist activity. Doses of these brain penetrant antagonists were selected from previous studies showing $<15$ min onset and $2-4 \mathrm{~h}$ duration in rodents. SR49059 prevented oxytocin-induced prosocial behavior [42] and hypothermia [39], whereas L-368,899 (which has brain penetration demonstrated by PET studies [43]), prevented anxiolytic effects of oxytocin in the open field [40], reduced conditioned disgust behavior during social interaction [44] and attenuated sexual motivation in male rats [45]. The crossover repeat within-subject design for dose-response and antagonist studies greatly reduced the number of rats required and the inter-individual variation of measurements made in line with the 3 R's principle.

Temperature microchips

Temperature microchips (Bio-Thermo idENTICHIP; AnimalCare Ltd; York, UK) were implanted s.c. $48 \mathrm{~h}$ before behavioral testing under brief manual restraint, to enable subsequent temperature recording via a digital chip reader with minimal disturbance to the animal, at 15 min intervals during assessment of LMA.

\section{Locomotor activity}

LMA was recorded as described previously [36]. In brief, rats were placed into individual Perspex boxes $(39 \times 23.5 \times 24.5 \mathrm{~cm}$ with removable wire lids) surrounded by a dual-level photobeam activity system (San Diego instruments, CA, USA). A single ambulation count was recorded for every two consecutive adjacent lower beam breaks and cumulative beam breaks were recorded in $5 \mathrm{~min}$ epochs for $2 \mathrm{~h}$. Oxytocin or vehicle were administered following $30 \mathrm{~min}$ arena habituation and in the antagonist study antagonists were administered 15 min prior to oxytocin.

Effect of oxytocin on PCP-induced hyperactivity, social interaction, and PFC and NAc dopamine and 5-HT efflux

Oxytocin at 0.03 and $0.1 \mathrm{mg} / \mathrm{kg}$ were selected for further investigation, as these doses did not produce confounding effects on ambulation and body temperature in dose-response studies described above. A separate group of rats ( $n=32$, Figure S1) was used to examine the effect of these two doses on PCP-induced hyperactivity, and on the basis of these findings $0.1 \mathrm{mg} / \mathrm{kg}$ oxytocin was administered 7 days later, prior to assessment of social interaction and USVs. The following week rats underwent 
stereotaxic surgery to implant microdialysis probes into the PFC and NAc and after 7 days recovery the effects of oxytocin on dopamine efflux from these brain regions was assessed. One week was left between each of the three protocols (Figure S1) to ensure complete drug wash-out and minimize any carry over effects from the previous procedure.

\section{Locomotor activity}

LMA was assessed on a single occasion as described above. Animals received oxytocin or vehicle after $30 \mathrm{~min}$ arena habituation, and vehicle or PCP (5.6 mg/kg i.p.; [18] an established dose to examine "antipsychotic-like" activity) 30 min later, resulting in four treatment combinations: vehicle + vehicle, PCP + vehicle, PCP + $0.03 \mathrm{mg} / \mathrm{kg}$ oxytocin, $\mathrm{PCP}+0.1 \mathrm{mg} / \mathrm{kg}$ ( $n=8 /$ group; betweensubjects design).

\section{Social interaction}

Two rats from different litters matched for weight $(<30 \mathrm{~g}$ difference) and treatment were sprayed on the nape with blue or pink hair dye $45 \mathrm{~min}$ prior to the trial to facilitate video tracking. Both rats received $0.1 \mathrm{mg} / \mathrm{kg}$ oxytocin or vehicle $45 \mathrm{~min}$ before placement into an unfamiliar circular arena $(75 \mathrm{~cm}$ diameter) under low light conditions (40 LUX) for $10 \mathrm{~min}[36,46]$. Ethovision (Noldus) was used to record interactive behaviors, including body sniffing, ano-genital sniffing, following, crawling over-and-under, lying side-by-side, pinning and boxing/biting, and to derive total social interaction. As the behavior of each rat depends on that of the partner, an average time was derived for each pair $(n=8$ per treatment) rather than each rat. Body temperature was recorded by telemetry immediately before and after social interaction.

USVs

Both $22 \mathrm{kHz}$ (alarm) and $50 \mathrm{kHz}$ (pro-social) USVs were recorded during social interaction as previously described [36]. An electret microphone (Emkay, Avisoft Bioacoustics, Germany) connected to an ultrasound detection unit (Ultrasound Gate, customized model 112 , Avisoft Bioacoustics, Berlin) was secured above the arena. The resulting signal was digitalized and saved as.wav files. Temporal and frequency characteristics of $50 \mathrm{kHz}$ calls were extracted using Avisoft analysis software (SAS-Lab Pro, v 4.38, Avisoft Bioacoustic, Berlin) and categorized offline into flat, step, or trill subtype, according to pattern analysis [14, 47]. Flat calls had peak frequency changes $\leq 5 \mathrm{kHz}$, although the difference between start and end frequencies could be $>5 \mathrm{kHz}$ if it had an upward or downward direction. Step calls had at least one short element $>5$ $\mathrm{kHz}$ higher or lower than the fundamental call. Trill calls had at least one frequency modulation with a longer element than step calls and/or a common zig-zag pattern often appearing as inverted-U shapes.

\section{Surgery and microdialysis}

One rat from each social interaction pair ( $n=16$ in total) was anaesthetized with isoflurane in $\mathrm{O}_{2}$ and $\mathrm{N}_{2} \mathrm{O}$, placed in a stereotaxic frame and CMA 12 guide cannulae (Linton Instrumentation; Diss, UK) implanted into the PFC and NAC (AP + 3.2, $\mathrm{L}-0.7$, $\mathrm{V}-2.3$, and $\mathrm{AP}+1.7, \mathrm{~L}+1.6, \mathrm{~V}-3.8$, respectively, from Bregma [48]). Guide cannulae, two copper-wire tethers, and stainless steel screws were secured in place with dental acrylic. Carprofen $(1 \mathrm{mg} /$ $\mathrm{kg}$ s.c.) was administered pre-surgery and lignocaine applied topically around sutures post surgery.

One week later, rats were briefly re-anaesthetized to insert microdialysis probes $(0.5 \mathrm{~mm} \times 4.0 \mathrm{~mm}$ membrane length with molecular cutoff 20,000 Da; CMA 12, Linton Instrumentation) into the guide cannulae. Probes were perfused continuously with artificial cerebral spinal fluid $(125 \mathrm{mM} \mathrm{NaCl}, 1.25 \mathrm{mM} \mathrm{KCl}, 0.5 \mathrm{mM}$ $\mathrm{MgCl}_{2}, 13.5 \mathrm{mM} \mathrm{NaHCO}, 0.2 \mathrm{mM} \mathrm{NaH} \mathrm{PO}_{4}, 0.90 \mathrm{mM} \mathrm{Na}{ }_{2} \mathrm{HPO}_{4}$, $0.30 \mathrm{mM} \mathrm{Na}_{2} \mathrm{SO}_{4}$, and $1.2 \mathrm{mM} \mathrm{CaCl}_{2}$ ) at $1 \mu \mathrm{l} / \mathrm{min}$ using dual-syringe pumps (Harvard Apparatus; Cambridge, UK). Rats were placed into an arena $(50 \mathrm{~cm}$ diameter, $45 \mathrm{~cm}$ height, containing sawdust bedding), with the microdialysis tubing attached to a dual channel swivel (Linton Instrumentation) and swivel mounted tether (Linton Instrumentation) allowing free movement [37]. The following day, three baseline samples were collected (in vials containing $5 \mu \mathrm{l} 0.1 \mathrm{M}$ perchloric acid (Fisher Scientific, UK) and $0.03 \%$ sodium metabisulphite (Sigma Aldrich, UK) and kept on dry ice until storage at $-80^{\circ} \mathrm{C}$ ) at $20 \mathrm{~min}$ intervals before and for $2 \mathrm{~h}$ after injection of either oxytocin $0.1 \mathrm{mg} / \mathrm{kg}$ s.c. or saline $(1 \mathrm{mg} / \mathrm{ml})$. At the end of the study, rats were euthanised with sodium pentobarbital (Euthatal) i.p. and brains dissected and stored in $4 \%$ paraformaldehyde at $4{ }^{\circ} \mathrm{C}$ for histological verification of probe placement.

\section{Analysis of monoamines}

Microdialysis samples were analyzed using High Performance Liquid Chromatography with electrochemical detection as described previously [37]. Defrosted samples were kept on ice before injection $(15 \mu \mathrm{l})$ into a Targa C18 $3 \mu \mathrm{M}$ column $(100 \times 1.0$ mm; Higgins Analytical) using a Perkin Elmer Series 200 autosampler (Antec Leyden, The Netherlands). Dopamine, 5-HT and their major metabolites; 3,4-dihydroxyphenylacetic acid (DOPAC), homovanillic acid (HVA), and 5-hydroxyindoleacetic acid (5-HIAA) were detected using a mobile phase $(20 \mathrm{mM}$ potassium dihydrogen phosphate, $20 \mathrm{mM}$ sodium acetate, $0.1 \mathrm{mM}$ ethylenediaminetetraacetic acid, $0.15 \mathrm{mM}$ octanesulfonic acid, and $10 \%$ methanol, pH 3.9) at $0.4 \mathrm{ml} / \mathrm{min}$ (Dionex $\mathrm{P} 680$ pump), and measured against standards with a DECADE II SDC Detector I (Antec; Leyden, The Netherlands) and Clarity software (Data Apex) using a potential of $+0.75 \mathrm{~V}$. The percentage change from baseline for every microdialysate molecule was calculated for each individual rat. PFC samples were excluded from one rat due to incorrect probe placement and two others because of flow disruption. In one rat NAc dopamine was below the detection limit; $n=6 / 7$ per group in the PFC, and $n=7 / 8$ in the NAC.

\section{Data analysis}

All analyses were performed by GraphPad Prism v7 (GraphPad Software Inc.) and SPSS (v24) and data were checked for normality and homogeneity of variance using Shapiro-Wilk's and Levene's tests, respectively. The time course of LMA and body temperature in studies that employed a within-subject design were analyzed using two-way repeated measures analysis of variance (ANOVA) (oxytocin dose-response study) or three-way repeated measures ANOVA (antagonist study) with oxytocin, antagonist (where used) and time as factors and total cumulative activity counts used repeated measures ANOVA. Data from PCP and microdialysis studies, which had a between-subject design, were analyzed by two-way ANOVA with treatment as a between-subjects factor and time as a repeated measure. ANOVA's were followed by Tukey's or Sidak multiple comparison post hoc tests where appropriate. Data are presented as mean \pm SEM and $P<0.05$ considered significant.

\section{RESULTS}

Effect of oxytocin on locomotor activity and body temperature During LMA rats habituated to the arena such that ambulation progressively decreased $\left(F_{(23,1012)}=86.20, P<0.0001\right)$ over $2 \mathrm{~h}$. Dose-response studies (Fig. 1a) showed acute oxytocin (0.03, 0.1, or $0.3 \mathrm{mg} / \mathrm{kg}$ ) had no effect, such that ANOVA revealed no significant main effect of treatment (data not shown). There was also no effect of oxytocin on total cumulative ambulatory activity over $90 \mathrm{~min} \quad\left(\mathrm{~F}_{(3,44)}=1.293, P=0.2888\right.$; one-way repeated measures ANOVA, Fig. 1b). Although the cumulative activity counts tended to be reduced by the highest dose $(0.3 \mathrm{mg} / \mathrm{kg})$ this failed to reach significance in this group.

During the LMA task, rat core body temperature modestly decreased $\left(F_{(7,308)}=31.82, P<0.0001\right)$, but post injection the 
A Dose-response protocol
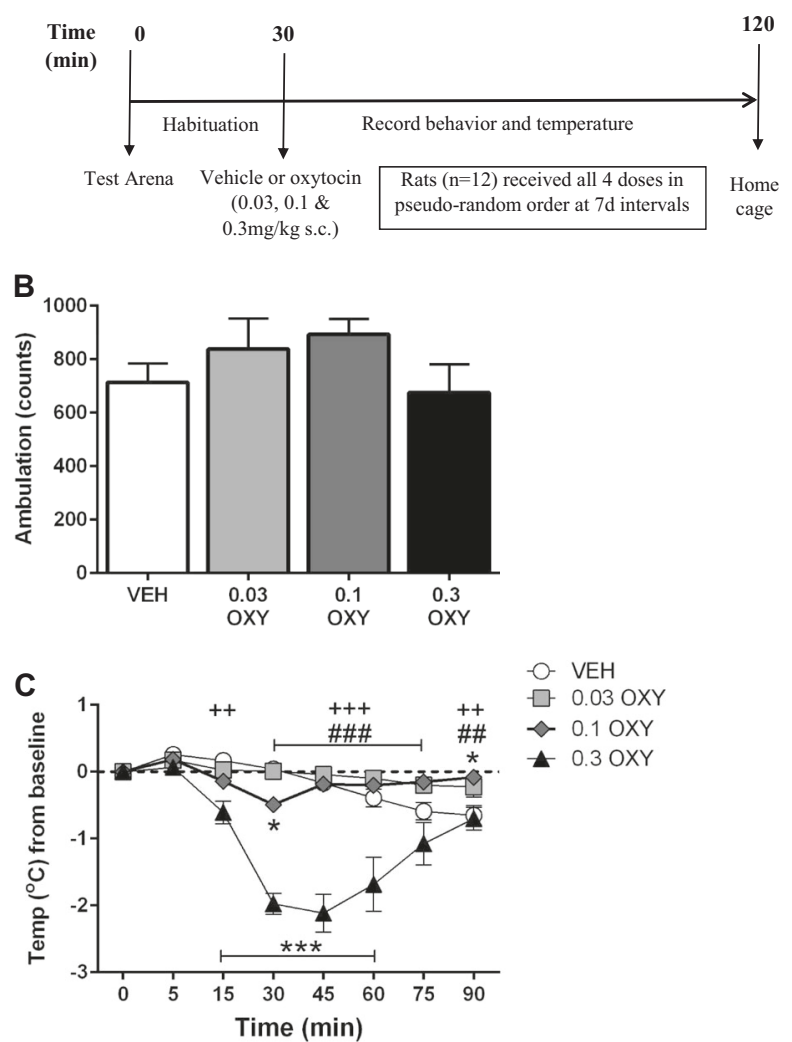

Fig. 1 Effect of oxytocin (OXY, 0.03, 0.1 , and $0.3 \mathrm{mg} / \mathrm{kg}$; s.c., administered after arena habituation) or vehicle (VEH, $0.154 \mathrm{M}$ saline $1 \mathrm{ml} / \mathrm{kg}$ ) administered according to the protocol shown in a on four occasions at 7 day intervals so that each rat received every dose on $\mathbf{b}$ total locomotor activity (LMA, cumulative ambulatory counts, mean \pm SEM), and c change in body temperature (from basal recorded 5 min pre injection, mean $\pm \mathrm{SEM},{ }^{\circ} \mathrm{C}$ ) in adult Lister-hooded rats $(n=12$, within-subjects design) recorded in an activity box for 90 min post injection. ${ }^{*} P<0.05,{ }^{* * *} P<0.001$ VEH vs. 0.3 or $0.1 \mathrm{mg} /$ kg OXY; ${ }^{\# \#} P<0.01,{ }^{\# \# \# ~} P<0.001,0.3 \mathrm{mg} / \mathrm{kg}$ OXY vs. $0.1 \mathrm{mg} / \mathrm{kg} \mathrm{OXY;}{ }^{+}$ ${ }^{+} P<0.010 .3 \mathrm{mg} / \mathrm{kg}$ OXY from $0.03 \mathrm{mg} / \mathrm{kg}$ OXY; Tukey's post hoc test

highest dose of oxytocin $(0.3 \mathrm{mg} / \mathrm{kg})$ produced significantly greater hypothermia than either saline or the two lower doses of oxytocin $\left(F_{(3,44)}=23.73, P<0.0001\right)$. There was also a treatment $\times$ time interaction $\left(\mathrm{F}_{(21,308)}=14.29 P<0.0001\right.$; ANOVA). Oxytocin at $0.3 \mathrm{mg} / \mathrm{kg}$ produced a significantly $(P<0.05,0.01$ or 0.001 ; Tukey's post hoc) greater decrease in temperature than vehicle between 15-60 min post injection, whereas $0.1 \mathrm{mg} / \mathrm{kg}$ slightly decreased temperature at the $30 \mathrm{~min}$ time point only (Fig. 1c).

Role of oxytocin and $\mathrm{V}_{1 \mathrm{a}}$ receptors in oxytocin-induced LMA and hypothermia

Following pre-treatment with either a selective oxytocin and $V_{1 a}$ receptor antagonist (according to the protocol shown in Fig. 2a) three-way ANOVA of the time course of LMA counts confirmed main effect of oxytocin $\left(F_{(1,11)}=34.776, P=0.0001\right)$ and time $\left(F_{(17,187)}=15.441, P=0.0001\right)$ but no significant effect of antagonist and no significant oxytocin $\times$ antagonist or oxytocin $\times$ antagonist $\times$ time interactions. Thus, for total cumulative activity counts post injection, $0.3 \mathrm{mg} / \mathrm{kg}$ oxytocin produced a modest (and in this group) a significant reduction in the cumulative locomotor activity counts from that seen in vehicle controls $(P<0.01)$, which was unaffected by pre-treatment with either L-368,889 or
A

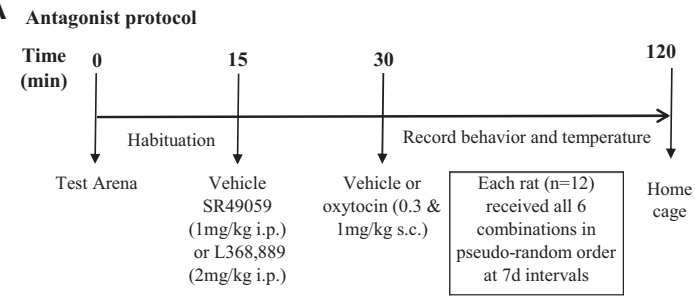

B

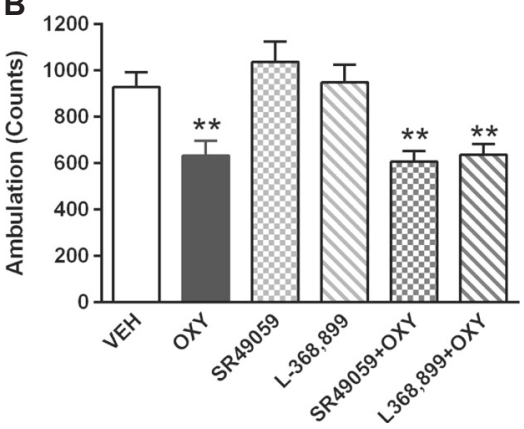

C

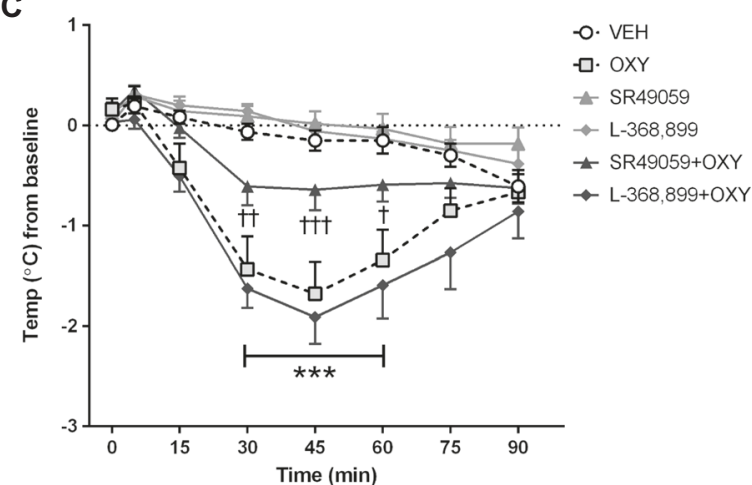

Fig. 2 Determination of the effect of pre-treatment with the selective $V_{1 a}$ receptor antagonist, SR49059 $(1 \mathrm{mg} / \mathrm{kg})$, or the selective oxytocin receptor antagonist, L-368,899 ( $2 \mathrm{mg} / \mathrm{kg})$, according to the experimental protocol shown in $\mathbf{a}$ on $\mathbf{b}$ the cumulative locomotor ambulatory counts, and $\mathbf{c}$ the change in body temperature $\left({ }^{\circ} \mathrm{C}\right)$ over $90 \mathrm{~min}$ following injection of oxytocin (OXY, $0.3 \mathrm{mg} / \mathrm{kg}$. s.c., administered $15 \mathrm{~min}$ after the antagonist) or vehicle (VEH, $1 \mathrm{ml} /$ $\mathrm{kg}$ saline). Data are presented as mean $\pm \mathrm{SEM}, n=12$ per treatment (within-subjects design). In $\mathbf{b}{ }^{* *} P<0.01$ from VEH + VEH controls. In c ${ }^{*} P<0.05$ and ${ }^{* * *} P<0.001$ from VEH + VEH controls, ${ }^{+} P<0.05,{ }^{++}$ $P<0.01$ and $^{+++} P<0.0010 .03 \mathrm{mg} / \mathrm{kg}$ OXY from $0.3 \mathrm{mg} / \mathrm{kg}$ OXY and ${ }^{\# \# \# P} P<0.0010 .1 \mathrm{mg} / \mathrm{kg}$ OXY from $0.3 \mathrm{mg} / \mathrm{kg}$ OXY, following Tukey's post hoc test

SR49059, neither of which affected activity on their own (Fig. 2b). At the same time similar analysis of body temperature (Fig. 2c) showed main effects of oxytocin $\left(F_{(1,11)}=59.162, P=0.001\right)$, antagonist $\left(F_{(2,22)}=5.046, P=0.016\right)$, and time $\left(F_{(7,77)}=47.072\right.$, $P=0.0001)$ and a significant oxytocin $\times$ antagonist $\times$ time interaction $\left(\mathrm{F}_{(14,154)}=4.156, P=0.0001\right)$. Oxytocin produced a marked $(\sim$ $2^{\circ} \mathrm{C}$ ) reduction in body temperature reaching a peak 30-60 min post injection, which was significantly lower than that in vehicle treated controls $(P<0.0001)$. The hypothermia induced by oxytocin from 30 to $60 \mathrm{~min}$ post injection was significantly attenuated $(P<0.05-P<0.001)$ by the $\mathrm{V}_{1 \mathrm{a}}$ receptor antagonist, SR49059, such that body temperature was not significantly different from vehicle at any time point in the SR49059 + oxytocin group. In contrast, the time course and magnitude of hypothermia produced by oxytocin was comparable in the absence and presence of the oxytocin receptor antagonist L-368,889. 


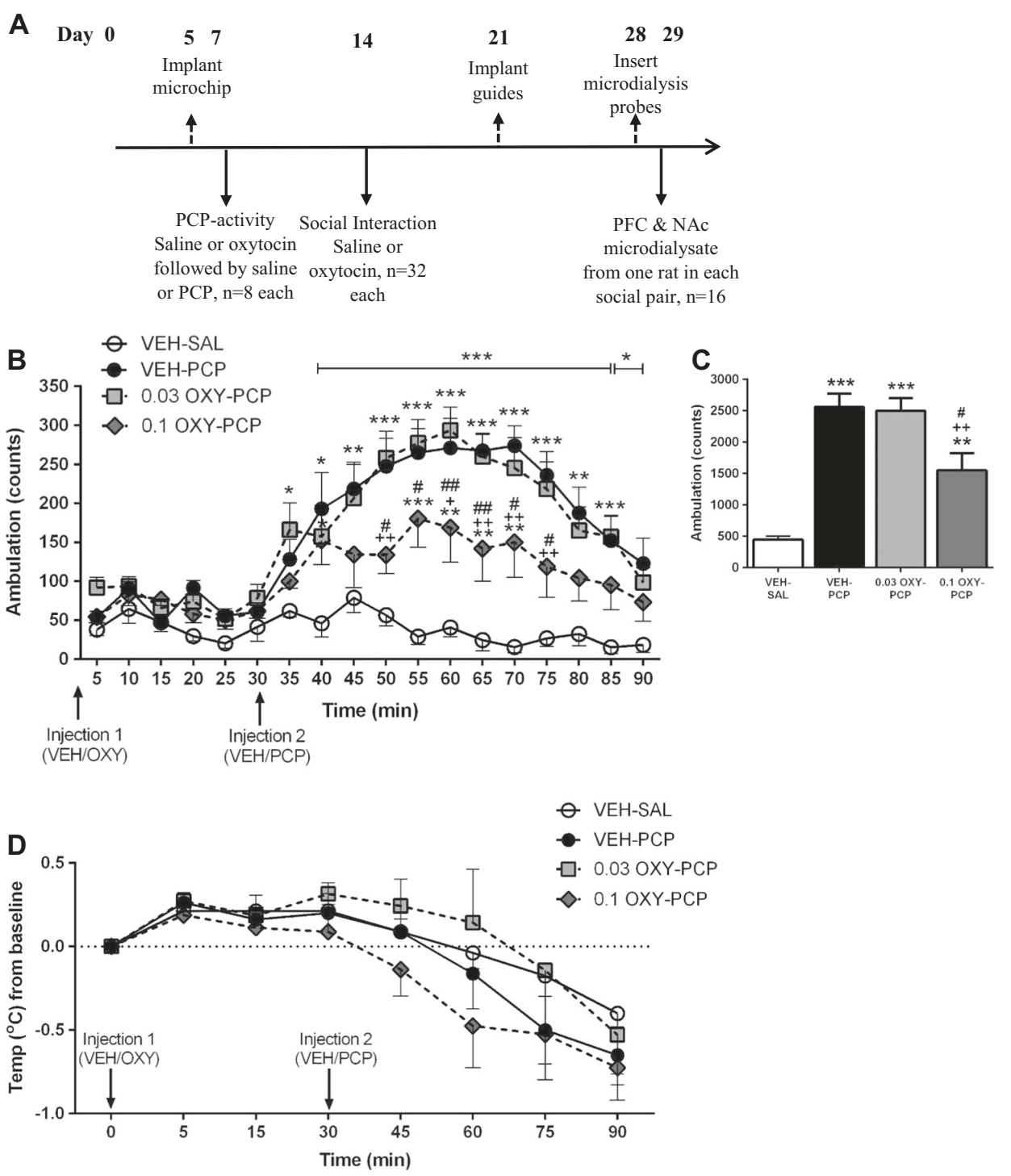

Fig. 3 a Experimental protocol used to consecutively examine the effect of oxytocin on phencyclidine-induced behavior (this figure), social interaction (Fig. 4), and prefrontal cortex and nucleus accumbens dopamine and 5-HT efflux by microdialysis (Fig. 5), for full details of the methods see Figure S1. Comparative effect of oxytocin (OXY, 0.03-0.1 mg/kg; s.c) and vehicle (VEH, $0.154 \mathrm{M} \mathrm{saline} 1 \mathrm{ml} / \mathrm{kg})$ on (mean \pm SEM) the $\mathbf{b}$ time course of phencyclidine (PCP, $5.6 \mathrm{mg} / \mathrm{kg}$; i.p.)-induced locomotor activity (LMA; cumulative counts/5 min epoch), $\mathbf{c}$ total ambulatory counts in $1 \mathrm{~h}$ (following injection with PCP/VEH), and $\mathbf{d}$ change in body temperature (from basal, 5 min prior to injection, ${ }^{\circ} \mathrm{C}$ ) in adult Listerhooded rats recorded in an activity box. In $\mathbf{b}$ and $\mathbf{c}{ }^{*} P<0.05,{ }^{* *} P<0.01,{ }^{* * *} P<0.001$ compared to VEH-SAL; ${ }^{+} P<0.05,{ }^{++} P<0.01 \mathrm{compared}$ with VEH-PCP; ${ }^{*} P<0.05,{ }^{\# \#} P<0.01$ compared with $0.03 \mathrm{mg} / \mathrm{kg}$ OXY-PCP; Tukey's post hoc) VEH $=$ saline vehicle, OXY $=0 x y$ tocin; $n=8$ per group (between-subjects design) as indicated VEH-VEH; VEH-PCP; OXY $0.03 \mathrm{mg} / \mathrm{kg}-\mathrm{PCP}$; OXY $0.1 \mathrm{mg} / \mathrm{kg}-\mathrm{PCP}$

Effect of oxytocin on PCP-induced hyperactivity

A separate group of rats was used to consecutively examine the effect of oxytocin on PCP-induced hyperactivity, social interaction, and PFC and NAc dopamine and 5-HT efflux by microdialysis according to the protocol in Fig. 3a. The highest dose of oxytocin attenuated the magnitude of the PCP-induced hyperactivity such that in $90 \mathrm{~min}$ following injection with oxytocin there was a significant main effect of time $\left(F_{(17,476)}=19.86, P<0.0001\right)$, treatment $\left(F_{(3,28)}=25.88, P<0.0001\right)$ and a treatment $\times$ time interaction $\left(\mathrm{F}_{(51,476)}=3.428, P<0.0001\right.$; Fig. 3b). There was no difference in the magnitude of LMA response between PCP rats that received pre-treatment with saline or the low dose of oxytocin. In contrast, $0.1 \mathrm{mg} / \mathrm{kg}$ oxytocin produced an $\sim 50 \%$ reduction, such that LMA was significantly less $(P<0.05$ or $P<$ 0.01 ) than both saline and low-dose oxytocin groups between 20 and $45 \mathrm{~min}$ after PCP injection.
As expected, the cumulative ambulatory count following injection of PCP was significantly greater than saline, such that there was a significant main effect of treatment $\left(F_{(3,28)}=24.34\right.$, $P<0.0001$; one-way ANOVA). Consistent with the time course data, only the highest dose of oxytocin $(0.1 \mathrm{mg} / \mathrm{kg})$ significantly attenuated PCP-induced hyperactivity compared with vehicle-PCP treated rats $(P<0.01$, Tukey's post hoc, Fig. $3 c)$, which was still significantly greater $(P<0.01)$ than the basal activity seen in saline controls.

The body temperature of rats measured during LMA gradually reduced over time $\left(F_{(7,189)}=20.17, P<0.0001\right.$; two-way repeated measures ANOVA) by $\sim 0.5^{\circ} \mathrm{C}$. However, there was no significant effect of oxytocin at either dose on the magnitude $\left(F_{(3,27)}=\right.$ 1.325, $P=0.2868$ ) or time course of the temperature change (treatment $\times$ time interaction $F_{(21,189)}=0.6389, \quad P=0.8860$; Fig. 3d). 

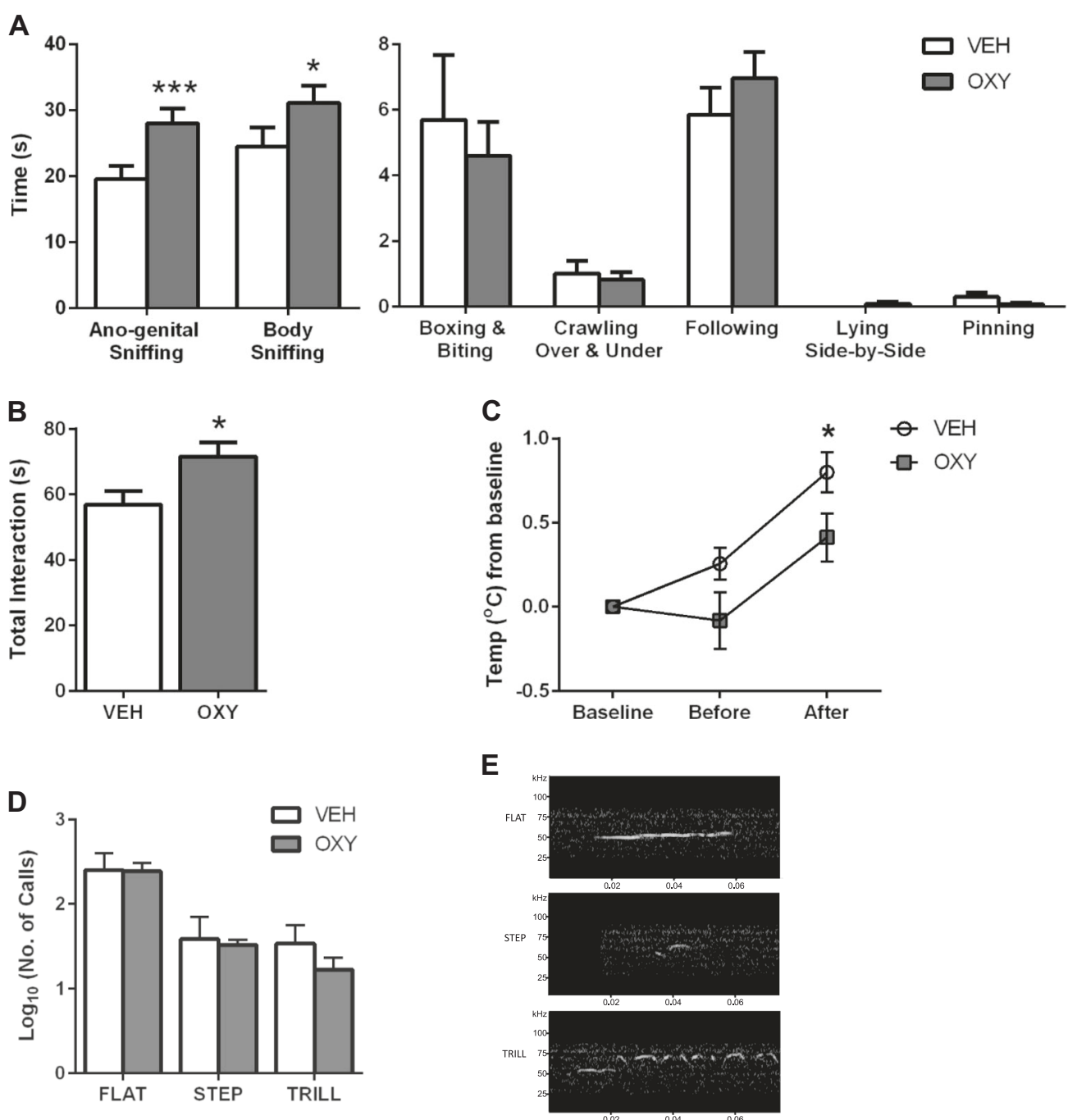

Fig. 4 Effect of oxytocin (OXY, $0.1 \mathrm{mg} / \mathrm{kg}$; s.c.) and vehicle (VEH, $0.154 \mathrm{M}$ saline $1 \mathrm{ml} / \mathrm{kg}$ ) on social interaction between two male Lister-hooded rats from different litters paired by similar weight and the same previous drug treatment, recorded over 10 min. a individual behaviors (s), $\mathbf{b}$ total time in social interaction (s), c body temperature change from basal (immediately prior to injection), before (45 min post injection) and after the interaction trial ( $55 \mathrm{~min}$ post injection as indicated; ${ }^{\circ} \mathrm{C}$ ) and $\mathbf{d}$ the number of pro-social $50 \mathrm{kHz}$ ultrasonic vocalizations (USVs) emitted by both rats in each pair. All data are presented as mean \pm SEM. e Representative spectrographs showing pro-social $50 \mathrm{kHz}$ USVs emitted from rat pairs defined into three subtypes; flat, step and trill, following Fast Fourier transformation and pattern analysis. a ${ }^{*} P=0.05$; Student's unpaired $t$-test. $c{ }^{*} P<0.05$ from OXY. d Following $\log _{10}$ transformation, ${ }^{*} P<0.05{ }^{* * *} P<0.001$ VEH vs. OXY; Sidak post hoc; VEH $=$ saline vehicle, $\mathrm{OXY}=0.1 \mathrm{mg} / \mathrm{kg}$ oxytocin; $n=8$ pairs/group. NB. A different time scale is used to show ano-genital and body sniffing from other, less frequent, behaviors

Effect of oxytocin on social interaction

Socially interactive behaviors including ano-genital sniffing, body sniffing, crawling over-and-under, following, pinning, lying sideby-side, as well as aggressive boxing/biting behavior were scored manually post trial. Both the total time spent undergoing prosocial behavior and engaged in each individual behavioral component was similar to that previously reported by us in group-housed control rats [36]. Comparison of vehicle and oxytocin-treated rats revealed significant main effects of both treatment $\left(F_{(1,98)}=7.001, P=0.0095\right)$ and behavioral component scored $\left(F_{(6,98)}=123, P<0.0001\right)$ and a treatment $\times$ behavior interaction $\left(\mathrm{F}_{(6,98)}=3.241, P=0.006\right)$. Rats given oxytocin $(0.1$ $\mathrm{mg} / \mathrm{kg})$ engaged in significantly more body sniffing $(P<0.05)$ and ano-genital sniffing ( $P<0.001$; Sidak post hoc) compared with saline controls (Fig. 4a) but there were no differences in any of the other five behavioral components.

Oxytocin also significantly increased the total time spent in social interaction (mean $\pm \mathrm{SEM}=71.6 \pm 4.3 \mathrm{~s}$ ), compared to those receiving vehicle $(56.9 \pm 4.1 \mathrm{~s} ; P<0.05$ unpaired Student's $t$-test; Fig. 4b).

Comparison of temperature change from baseline, before, and after social interaction showed that core body temperature increased during the trial $\left(F_{(2,60)}=23.3, P<0.0001\right)$. Oxytocin reduced the extent of hyperthermia $\left(F_{(1,30)}=5.011, P=0.0328\right)$ such that there was a treatment $\times$ time interaction $\left(F_{(2,60)}=2.41\right.$, $P=0.0985)$. The temperature difference between vehicle and oxytocin-treated rats was close to significance before $(P=0.0954)$ but reached significance ( $P=<0.05$; Sidak test; Fig. $4 \mathrm{c})$ immediately after the social interaction trial.

Effect of oxytocin on USVs

Pro-social $50 \mathrm{kHz}$ USVs emitted from each rat pair during social interaction was quantified according to three defined subtypes; flat, step, and trill [49] following Fast Fourier transformation and pattern analysis (Fig. 4e). A two-way ANOVA of USVs following a $\log _{10}$ transformation (to normalize data), revealed a significant 

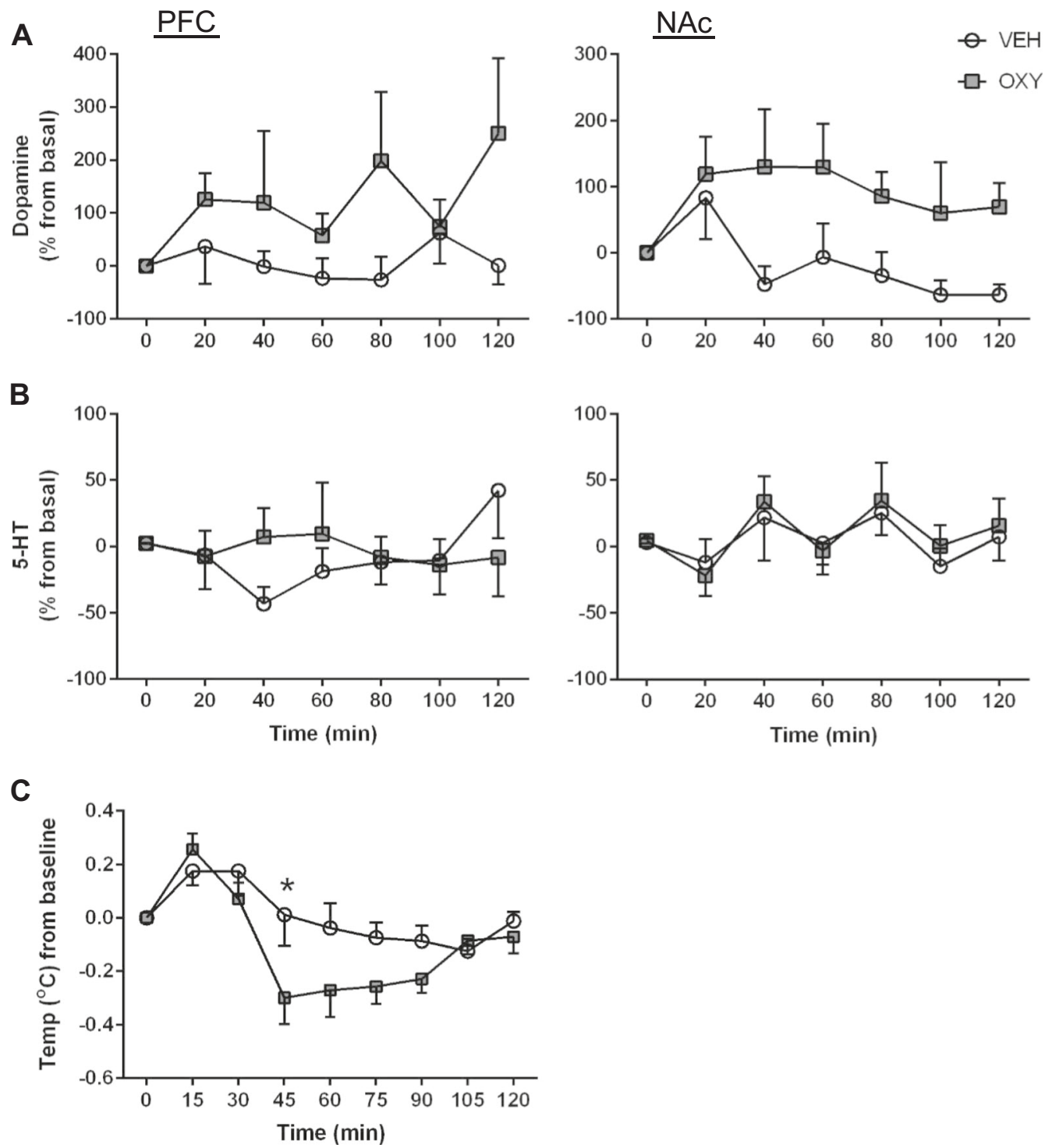

Fig. 5 Comparison of the effects of oxytocin (OXY, $0.1 \mathrm{mg} / \mathrm{kg}$; s.c.) or vehicle (VEH, $0.154 \mathrm{M}$ saline $1 \mathrm{ml} / \mathrm{kg})$ on a dopamine and $\mathbf{b}$ serotonin (5$\mathrm{HT}$ ) overflow (mean $\pm \mathrm{SEM}, \mathrm{pmol} / \mathrm{ml}$ ) in the prefrontal cortex (PFC) and nucleus accumbens (NAc) measured by microdialysis, and concomitant c core body temperature (mean $\left.\pm \mathrm{SEM} ;{ }^{\circ} \mathrm{C}\right)$ in freely-moving rats. a Changes to dopamine from baseline in the PFC $(0.0728 \mathrm{pmol} / \mathrm{ml})$ and $\mathrm{NAc}$ $(0.176 \mathrm{pmol} / \mathrm{ml})$ over the $2 \mathrm{~h}$ period. b Changes in 5-HT levels from baseline in the PFC $(2.212 \mathrm{pmol} / \mathrm{ml})$ and NAc $(3.677 \mathrm{pmol} / \mathrm{ml})$. PFC: Dopamine: $n=7 \mathrm{VEH}, n=6$ OXY, 5-HT: $n=7 \mathrm{VEH}, n=6$ OXY; NAc: Dopamine: $n=7$ VEH, $n=7$ OXY, 5-HT: $n=8$ VEH, $n=8$ OXY; VEH = saline vehicle, $\mathrm{OXY}=0.1 \mathrm{mg} / \mathrm{kg}$ oxytocin; PFC; Prefrontal Cortex, NAc; Nucleus Accumbens. $c{ }^{*} P<0.05 \mathrm{VEH}$ vs OXY; Sidak post hoc. VEH $=$ saline vehicle, $\mathrm{OXY}=0.1 \mathrm{mg} / \mathrm{kg}$ oxytocin; $n=8$ per treatment group; between-subjects design

main effect of the call type $\left(F_{(2,42)}=18.75, P<0.0001\right)$ emitted (flat being more frequent than step or trill) but this was unaltered by oxytocin treatment $\left(F_{(1,42)}=0.8109, P=0.3730\right.$; Fig. $\left.4 d\right)$. No rats emitted any $22 \mathrm{kHz}$ USVs, so no analysis could be performed on these calls.

Effect of oxytocin on PFC and NAc dopamine and 5-HT efflux Pre-injection basal dopamine and 5-HT levels (average of initial triplicates) were determined in the PFC and NAc and used to calculate the percentage change for each monoamine. Compared with initial basal dopamine levels $(0.0728$ and $0.176 \mathrm{pmol} / \mathrm{ml}$ in the PFC and NAc, respectively) oxytocin $(0.1 \mathrm{mg} / \mathrm{kg})$ produced a significant $\left(\mathrm{F}_{(1,12)}=7.983, P=0.0153\right)$ persistent $(\sim 100 \%)$ elevation of overflow in the NAc, but the much more varied trend to increase DA in the PFC did not reach significance $\left(F_{(1,11)}=4.254\right.$, $P=0.0634$; Fig. 5a). In order to ascertain if the effect on cortical dopamine could be more transient than the NAc analysis was also performed on the data in the first 60 and 80 min post injection but this was also not significant. There was no significant effect of time nor any treatment $\times$ time interaction $(P>0.05)$ in either brain region.

In contrast, basal 5-HT levels (PFC and NAc being 2.212 and $3.677 \mathrm{pmol} / \mathrm{ml}$, respectively) were unaltered by oxytocin injection such that there was no significant main effect of treatment or time nor any treatment $\times$ time interaction in either the PFC $\left(F_{(1,11)}=\right.$ $0.06091, P=0.8096)$ or NAc $\left(F_{(1,14)}=0.08213, P=0.7786\right.$; Fig. $\left.5 b\right)$. Microdialysate levels of the major metabolites of DA and 5-HT (DOPAC, HVA, and 5-HIAA) were also unaltered from basal levels by oxytocin or vehicle and remained stable across time post injection (Figure S2). As extracellular levels of DOPAC, HVA, and 5HIAA reflect intracellular metabolism of their respective neurotransmitter, microdialysate levels of these metabolites would not be expected to mirror nor provide an index of corresponding neurotransmitter release. 
Core body temperature slowly and progressively decreased over $2 \mathrm{~h}$ post injection $\left(\mathrm{F}_{(8,104)}=11.05, P<0.0001\right)$ and although there was no main effect of treatment $\left(\mathrm{F}_{(1,13)}=3.129, P=0.1003\right)$, there was a significant time $\times$ treatment interaction $\left(F_{(8,104)}=\right.$ $2.482, P=0.0167$; two-way repeated measures ANOVA). Oxytocin only caused significantly greater hypothermia than vehicle at 45 min post injection $(P<0.05$; Sidak post hoc; Fig. $5 c)$.

\section{DISCUSSION}

This study demonstrates the ability to dose differentiate the effect of systemic oxytocin injection on reversal of PCP-induced LMA and pro-social behavior from hypothermia and "sedative-like" hypoactivity in Lister-hooded rats. Importantly oxytocin enhanced social interaction without simultaneously altering $50 \mathrm{kHz}$ pro-social calls, suggesting that this behavior resulted from direct neuronal modulation by oxytocin. Accompanying microdialysis data suggest this may be mediated, at least in part, by selective enhancement of dopamine (and not serotonin) release preferentially in the NAc, and not the PFC, from mesocorticolimbic circuits involved in associative/reward behavior.

Although as little as $0.01 \%$ of systemic oxytocin may reach the rat CNS because of poor penetration of the $\operatorname{BBB}[5,50]$ and the estimated blood half-life is $\sim 5 \mathrm{~min}$, the cerebrospinal fluid half-life is considerably longer (at least $20 \mathrm{~min}$ [51]) and could provide a compartment for more sustained CNS actions [32] similar to those reported herein. Several previous studies show intranasal and intracerebral oxytocin administration enhances rodent social behavior [13, 52-54], which may also occur in humans [55-57]. As the rat pituitary contains $\sim 1 \mu \mathrm{g}$ oxytocin, even minimal brain penetration of supraphysiological amounts given systemically could alter brain function, since as little as $1 \mathrm{ng}$ intracerebroventricular oxytocin produces behavioral effects in rodents [58]. In addition, exogenous oxytocin may activate peripheral afferents or subfornical organ projections to the paraventricular nucleus [59] as well as acting directly on magnocellular neurons, all of which may enhance endogenous oxytocin release by positive feedback [60] resulting in diffuse dendritic release [51] and a prolonged effect. Consistent with this proposal functional magnetic resonance imaging BOLD in rats has suggested systemic oxytocin does not activate the same receptor-rich areas as intracerebroventicular administration [61] and following subcutaneous injection oxytocin levels double in amygdala and hippocampal microdialysates for 30-60 min [62]. The current study shows robust changes in behavior and increased NAc dopamine release following subcutaneous oxytocin injection in Lister-hooded rats during a similar time period.

Dose-response studies established that $0.3 \mathrm{mg} / \mathrm{kg}$ s.c. oxytocin produced hypothermia in Lister-hooded rats $\left(-2{ }^{\circ} \mathrm{C}\right.$, peaking at 30-60 min post injection) and even this high dose caused limited suppression of activity; causing a significant reduction in cumulative LMA over $90 \mathrm{~min}$ post injection in one of the two groups examined. By comparison, lower doses $(0.03$ or $0.1 \mathrm{mg} / \mathrm{kg}$ ) of oxytocin produced little hypothermia and no effect on LMA. Thus the current observation that $\sim 0.3 \mathrm{mg} / \mathrm{kg}$ s.c. oxytocin is at the threshold where attenuation of locomotor activity reaches significance in Lister-hooded rats is consistent with findings by Hicks et al. [39] and Klenerova et al. [40] in Wistar, and Angioni et al. [38] in Sprague-Dawley rats, where hypoactivity only occurred with 1 or $2 \mathrm{mg} / \mathrm{kg}$ i.p. oxytocin. Similarly, in behavior and microdialysis studies herein, $0.1 \mathrm{mg} / \mathrm{kg}$ oxytocin had no effect on activity and caused a very small $\left(0.2^{\circ} \mathrm{C}\right)$ decrease in body temperature. Of particular note the hypothermia recorded with the highest dose of oxytocin $(0.3 \mathrm{mg} / \mathrm{kg})$ in this study was markedly attenuated by the selective $\mathrm{V}_{1 \mathrm{a}}$ receptor antagonist SR49059 but unaffected by the oxytocin antagonist L-368,899, which is brain penetrant [63] and attenuates oxytocin-induced hypoactivity in Wistar rats at the dose used in this study [40].
Previous biotelemetry studies [39] also suggest the thermoregulatory effects of systemic oxytocin primarily involve $\mathrm{V}_{1 \mathrm{a}}$ receptor activation and support the proposal that the pro-social and microdialysis effects reported in this study (with lower doses that cause little hypothermia) may be mediated primarily by oxytocin receptor and not $\mathrm{V}_{1 \mathrm{a}}$ receptor activation. In accord with a previous report in Wistar rats [40] the "sedative-like" hypoactivity seen with the highest dose of oxytocin was only partially attenuated SR49059 or L-368,889. Therefore, this hypoactivity could be mediated by oxytocin acting at distinct receptors, potentially the $\mathrm{V}_{1 \mathrm{~b}}$ (located in the pituitary in adults) for which it has modest affinity, or allosteric modulation of dopamine binding at oxytocin$D_{2}$ dopamine receptor heterodimers [64], if these exist in vivo. In contrast, in Sprague-Dawley rats LMA suppression produced by 2 $\mathrm{mg} / \mathrm{kg}$ i.p. oxytocin was mimicked by microinjection into the substantia nigra and prevented by intracerebroventricular injection of an oxytocin antagonist, and therefore could result from activation of oxytocin receptors on nigrostriatal dopaminergic neurons [38].

At $0.1 \mathrm{mg} / \mathrm{kg}$ oxytocin markedly attenuated PCP-induced hyperactivity, whereas the low dose $(0.03 \mathrm{mg} / \mathrm{kg})$ had no effect. No previous study has examined the effect of oxytocin on NMDA antagonist-induced hyperactivity, but notably oxytocin $(2 \mathrm{mg} / \mathrm{kg}$ i. p.) decreased methamphetamine-induced hyperactivity in rats [65] accompanied by attenuation of induced Fos protein expression in the subthalamic nucleus and NAc core [66], suggesting these regions may be involved. Furthermore, oxytocin also attenuated cocaine-induced hyperactivity and the concomitant reduction in post-mortem NAc dopamine content in mice [67]. Both PCP and methamphetamine significantly increased ambulatory activity, and PFC and NAc microdialysate dopamine, and $5-\mathrm{HT}$ levels in rodents following acute injection [20, 21]. Furthermore, dopamine release measured by chronoamperometry was enhanced by oxytocin infusion into the NAc and VTA $[25,27]$, suggesting that oxytocin can activate mesolimbic dopaminergic neurons. As both PCP and oxytocin enhance NAc dopamine release it appears paradoxical that this could explain oxytocin attenuation of PCP-induced LMA. However, when given in combination, oxytocin reduces the methamphetamine increase in NAc dopamine turnover in mice [68]. Compared with amphetamine, PCP more markedly elevates NAc microdialysate 5-HT and PCP-induced LMA is attenuated by $5-\mathrm{HT}_{2 \mathrm{~A}}$ receptor antagonists [21]. However, as oxytocin did not alter NAC or PFC 5$\mathrm{HT}$ release in the current study it is unlikely that direct modulation of serotonergic function contributes to the attenuation of PCPLMA observed. Although a small decrease $\left(0.2-0.4^{\circ} \mathrm{C}\right)$ in body temperature was seen $30-45 \mathrm{~min}$ after $0.1 \mathrm{mg} / \mathrm{kg}$ oxytocin administration in the current dose-response and microdialysis studies, this is unlikely to account for the selective elevation in NAc DA overflow observed since hypothermia [69] reduces striatal DA levels in microdialysates. Acute PCP activates PFC glutamatergic efferents to the VTA, which also contribute to the motoric enhancement observed [70]. The locomotor hyperactivity and elevation in microdialysate dopamine efflux in the NAc are both attenuated by injection of the dopamine receptor antagonist flupenthixol into the NAc [71], consistent with corticolimbic pathways contributing to PCP hyperactivity. Furthermore, oxytocin attenuates the medial PFC methamphetamine-induced increase in glutamate in an oxytocin receptor-sensitive manner [72]. So far, no studies have examined whether a similar interaction occurs with PCP. Oxytocin-induced facilitation of mesolimbic dopaminergic function and accompanying facilitation of NAc dopamine release have been shown to regulate maternal behavior and chemical lesions or microinjection of dopamine antagonists disrupt this [25-27]. Oxytocin containing parvocellular neurons of the paraventricular nucleus project to the NAc and VTA, whereas oxytocin neurons of the medial preoptic area innervate the VTA whose dopamine neurons in turn innervate the NAC and the PFC [27]. 
Both the VTA and NAc have oxytocin receptors, which would be targets of peripheral administration or brain penetrant drugs $[2,27]$. By using oxytocin receptor Cre mice [73] it has been shown that glutamatergic neurons in the VTA also express oxytocin receptors and oxytocin likely also modulates glutamatergic neuronal function, as oxytocin receptor knockout mice show larger deficits in sensorimotor gating following PCP than wildtype mice [74]. Thus, glutamatergic modulation by oxytocin might also contribute to attenuate PCP-induced LMA.

Activation of oxytocinergic neurons in the PVN and supraoptic hypothalamic nuclei (which express $5-\mathrm{HT}_{1 \mathrm{~A}}$ receptors [75]) by input from dorsal raphe $5-\mathrm{HT}$ neurons promotes oxytocin release from their terminals in the NAc serving to enhance social reinforcement $[22,76,77]$. In addition, oxytocin heteroreceptors enhances 5-HT release from raphe nerve terminals in the NAc, reinforcing the rewarding property of social interaction in mice [24]. Although NAc DA may signal acute reward reinforcement, serotonergic neuronal activation in the NAc may contribute to delayed gratification reward and social attachment [22]. Consistent with the current microdialysis observations oxytocin may have little impact on basal 5-HT release but only enhance NAc 5-HT during social reinforcement. Consistent with this proposal the oxytocin antagonist, tocinoic acid, does little to social interaction when given alone but attenuates the facilitation of interaction produced by MDMA or the 5- $\mathrm{HT}_{1 \mathrm{~A}}$ agonist 8-OHDPAT [78].

In this study, oxytocin $(0.1 \mathrm{mg} / \mathrm{kg})$ increased pro-social interaction most notably owing to increased ano-genital and body sniffing. Rodents are thought to sniff ano-genital regions of conspecifics as part of social recognition to decode identity, and an increase might reflect altered acceptance of familiarity of strangers and facilitate social reciprocity. Similar enhancement of total pro-social behavior has previously been observed in both mice and rats [11, 42, 79-81] following oxytocin administration. The only previous report of peripheral oxytocin $(0.5$ $\mathrm{mg} / \mathrm{kg}$ i.p. in Long Evans rats) on social interaction found increased lying side-by-side and reduced ano-genital sniffing, both prevented by the $\mathrm{V}_{1 \text { a }}$ receptor antagonist, SR49059, but not by the oxytocin antagonist, C25 [42]. Several groups have shown a range of doses of both oxytocin and vasopressin produce similar pro-social behavior during social interaction, also implicating $V_{1 a}$ receptors or downstream signaling cross-talk between oxytocin and $V_{1 a}$ receptors in these effects in rats and hamsters $[42,82,83]$. The precise brain regions involved in the pro-social effect is unclear but both peripheral and microinjection of the oxytocin antagonist L-368,899 into the NAC reduced social preference in adult male mice in a social reward paradigm [24]. By using viral vectors, it has been shown that social interaction enhances activity of PVN oxytocin neurons innervating VTA neurons projecting to the NAC, which can be attenuated by an oxytocin receptor antagonist [84], suggesting oxytocin receptors are also involved. The potential sites of interaction of oxytocin with circuits connecting the NAc via activation of oxytocin and/or $\mathrm{V}_{1 \mathrm{a}}$ receptors and consequential alterations in dopamine, GABA, and glutamate are elegantly discussed in a recent review [85] and further evaluation such as by microinjection with selective antagonists or lesions using the neurotoxin, saporin-oxytocin, would help delineate the brain region/s and receptor/s involved.

In contrast to effects on social behavior, oxytocin did not concomitantly alter the number or pattern of high frequency USVs consistent with a previous report that arginine-vasopressin failed to alter $50 \mathrm{kHz}$ USVs in rats [86]. Rats emit $50 \mathrm{kHz}$ USVs during positive behavioral or rewarding situations (including social play and sexual behavior), which is thought to reflect positive affective state [49], and if played back to rats induce approach behavior [87]. Furthermore, $50 \mathrm{kHz}$ USVs are attenuated by dopamine $D_{1}$ and $D_{2}$ antagonists and 6hydroxydopamine lesion of the VTA dopamine neurons [88].
As USVs were unaltered by oxytocin herein, the change in social behavior between rat pairs probably results from activation of mesocorticolimbic circuits [16] and is not driven by altered communicative calls.

Despite evidence that high doses of oxytocin cause receptor internalization [80, 89], repeated low-dose oxytocin exposure causes enduring increases in social interaction in rats [83], potentially resulting from synaptic plasticity enhancing the serotonergic input to the NAc, reinforcing the rewarding impact of social behavior [24]. The extent of BBB penetration following intranasal oxytocin administration in man is controversial [32]. This study in rats show that peripheral oxytocin administration can enhance social interaction and increase NAc dopamine overflow, without producing accompanying sedative or thermoregulatory effects, warranting further investigation as a potential therapy for antecedent social behavioral deficits such as seen in autism spectrum disorder and schizophrenia.

\section{ACKNOWLEDGEMENTS}

We thank Clare Spicer for technical assistance. Studies were designed by KCFF and MVK with input from TMB, LS, and DA. Experimental work was undertaken the University of Nottingham by SK, KCFF, SW, and AW. The first draft of the manuscript was produced by SK, MVK, and KCFF and all authors contributed to production of the final version.

\section{ADDITIONAL INFORMATION}

Supplementary Information accompanies this paper at (https://doi.org/10.1038/ s41386-018-0171-0).

Competing interests: We declare that, except for income received from their primary employer, no financial support or compensation has been received from any individual or corporate entity over the past three years for research or professional service and there are no personal financial holdings that could be perceived as constituting a potential conflict of interest. The contribution to this work made by SK, MVK, and KCFF was financially supported by Roche. The University of Nottingham BBSRC DTP provided funding for Adele Edwards and Stuart Williams to perform dose-response studies with oxytocin while on laboratory rotations. LJS, TMB, and DA are employed by Hoffmann-la Roche.

Publisher's note: Springer Nature remains neutral with regard to jurisdictional claims in published maps and institutional affiliations.

\section{REFERENCES}

1. Neumann I, Russell JA, Landgraf R. Oxytocin and vasopressin release within the supraoptic and paraventricular nuclei of pregnant, parturient and lactating rats: a microdialysis study. Neuroscience. 1993;53:65-75.

2. Smith CJ, Poehlmann ML, Li S, Ratnaseelan AM, Bredewold R, Veenema AH. Age and sex differences in oxytocin and vasopressin $\mathrm{V} 1 \mathrm{a}$ receptor binding densities in the rat brain: focus on the social decision-making network. Brain Struct Funct. 2017:222:981-1006.

3. Borthwick AD. Oral oxytocin antagonists. J Med Chem. 2010;53:6525-38.

4. Grinevich V, Knobloch-Bollmann HS, Eliava M, Busnelli M, Chini B. Assembling the Puzzle: pathways of oxytocin signaling in the brain. Biol Psychiatry. 2016;79:155-64.

5. Meyer-Lindenberg A, Domes G, Kirsch P, Heinrichs M. Oxytocin and vasopressin in the human brain: social neuropeptides for translational medicine. Nat Rev Neurosci. 2011;12:524-38.

6. Romano A, Tempesta B, Micioni Di Bonaventura MV, Gaetani S. From autism to eating disorders and more: the role of oxytocin in neuropsychiatric disorders. Front Neurosci. 2015;9:497.

7. Bradley ER, Woolley JD. Oxytocin effects in schizophrenia: reconciling mixed findings and moving forward. Neurosci Biobehav Rev. 2017;80:36-56.

8. Kirsch P. Oxytocin in the socioemotional brain: implications for psychiatric disorders. Dialogues Clin Neurosci. 2015;17:463-76.

9. Pedersen CA, Prange AJ Jr. Induction of maternal behavior in virgin rats after intracerebroventricular administration of oxytocin. Proc Natl Acad Sci USA. 1979:76:6661-5.

10. Insel TR, Hulihan TJ. A gender-specific mechanism for pair bonding: oxytocin and partner preference formation in monogamous voles. Behav Neurosci. 1995;109:782-9. 
11. Calcagnoli F, Meyer N, de Boer SF, Althaus M, Koolhaas JM. Chronic enhancement of brain oxytocin levels causes enduring anti-aggressive and pro-social explorative behavioral effects in male rats. Horm Behav. 2014;65:427-33.

12. Grippo AJ, Trahanas DM, Zimmerman RR 2nd, Porges SW, Carter CS. Oxytocin protects against negative behavioral and autonomic consequences of long-term social isolation. Psychoneuroendocrinology. 2009;34:1542-53.

13. Insel TR, Winslow JT. Central administration of oxytocin modulates the infant rat's response to social isolation. Eur J Pharmacol. 1991;203:149-52.

14. Simola N. Rat ultrasonic vocalizations and behavioral neuropharmacology: from the screening of drugs to the study of disease. Curr Neuropharmacol. 2015;13:164-79.

15. Wohr M, Houx B, Schwarting RK, Spruijt B. Effects of experience and context on 50-kHz vocalizations in rats. Physiol Behav. 2008;93:766-76.

16. Wohr M, Schwarting RK. Affective communication in rodents: ultrasonic vocalizations as a tool for research on emotion and motivation. Cell Tissue Res. 2013;354:81-97

17. Wright JM, Gourdon JC, Clarke PB. Identification of multiple call categories within the rich repertoire of adult rat $50-\mathrm{kHz}$ ultrasonic vocalizations: effects of amphetamine and social context. Psychopharmacol (Berl). 2010;211:1-13.

18. Hackler EA, Byun NE, Jones CK, Williams JM, Baheza R, Sengupta S, et al. Selective potentiation of the metabotropic glutamate receptor subtype 2 blocks phencyclidine-induced hyperlocomotion and brain activation. Neuroscience. 2010;168:209-18.

19. Jentsch JD, Roth RH. The neuropsychopharmacology of phencyclidine: from NMDA receptor hypofunction to the dopamine hypothesis of schizophrenia. Neuropsychopharmacology. 1999;20:201-25.

20. Li Z, Boules M, Williams K, Peris J, Richelson E. The novel neurotensin analog NT69L blocks phencyclidine (PCP)-induced increases in locomotor activity and PCP-induced increases in monoamine and amino acids levels in the medial prefrontal cortex. Brain Res. 2010;1311:28-36.

21. Millan MJ, Brocco M, Gobert A, Joly F, Bervoets K, Rivet J, et al. Contrasting mechanisms of action and sensitivity to antipsychotics of phencyclidine versus amphetamine: importance of nucleus accumbens 5-HT2A sites for PCP-induced locomotion in the rat. Eur J Neurosci. 1999;11:4419-32.

22. Fernandez $M$, Mollinedo-Gajate I, Penagarikano $O$. Neural circuits for social cognition: implications for autism. Neuroscience. 2018;370:148-62.

23. Skuse DH, Gallagher L. Dopaminergic-neuropeptide interactions in the social brain. Trends Cogn Sci. 2009;13:27-35.

24. Dolen G, Darvishzadeh A, Huang KW, Malenka RC. Social reward requires coordinated activity of nucleus accumbens oxytocin and serotonin. Nature. 2013;501:179-84.

25. Shahrokh DK, Zhang TY, Diorio J, Gratton A, Meaney MJ. Oxytocin-dopamine interactions mediate variations in maternal behavior in the rat. Endocrinology. 2010;151:2276-86.

26. Insel TR. A neurobiological basis of social attachment. Am J Psychiatry. 1997;154:726-35.

27. Love TM. Oxytocin, motivation and the role of dopamine. Pharmacol Biochem Behav. 2014;119:49-60.

28. Aragona BJ, Liu Y, Yu YJ, Curtis JT, Detwiler JM, Insel TR, et al. Nucleus accumbens dopamine differentially mediates the formation and maintenance of monogamous pair bonds. Nat Neurosci. 2006;9:133-9.

29. Gingrich B, Liu Y, Cascio C, Wang Z, Insel TR. Dopamine D2 receptors in the nucleus accumbens are important for social attachment in female prairie voles (Microtus ochrogaster). Behav Neurosci. 2000;114:173-83.

30. Liu Y, Wang ZX. Nucleus accumbens oxytocin and dopamine interact to regulate pair bond formation in female prairie voles. Neuroscience. 2003;121:537-44.

31. Young KA, Liu Y, Gobrogge KL, Wang H, Wang Z. Oxytocin reverses amphetamine-induced deficits in social bonding: evidence for an interaction with nucleus accumbens dopamine. J Neurosci. 2014;34:8499-506.

32. Leng G, Ludwig M. Intranasal oxytocin: myths and delusions. Biol Psychiatry. 2016;79:243-50.

33. Feifel D, Shilling PD, MacDonald K. A review of oxytocin's effects on the positive, negative, and cognitive domains of schizophrenia. Biol Psychiatry. 2016;79:222-33.

34. Uhl-Bronner S, Waltisperger E, Martinez-Lorenzana G, Condes Lara M, FreundMercier MJ. Sexually dimorphic expression of oxytocin binding sites in forebrain and spinal cord of the rat. Neuroscience. 2005;135:147-54.

35. Kilkenny C, Browne W, Cuthill IC, Emerson M, Altman DG. Animal research: reporting in vivo experiments: the ARRIVE guidelines. $\mathrm{Br} J$ Pharmacol. 2010;160:1577-79.

36. Watson DJ, King MV, Gyertyan I, Kiss B, Adham N, Fone KC. The dopamine D(3)preferring $D(2) / D(3)$ dopamine receptor partial agonist, cariprazine, reverses behavioural changes in a rat neurodevelopmental model for schizophrenia. Eur Neuropsychopharmacol. 2016;26:208-24.
37. Shortall SE, Spicer CH, Ebling FJ, Green AR, Fone KC, King MV. Contribution of serotonin and dopamine to changes in core body temperature and locomotor activity in rats following repeated administration of mephedrone. Addict Biol. 2016;21:1127-39.

38. Angioni L, Cocco C, Ferri GL, Argiolas A, Melis MR, Sanna F. Involvement of nigral oxytocin in locomotor activity: A behavioral, immunohistochemical and lesion study in male rats. Horm Behav. 2016;83:23-38.

39. Hicks C, Ramos L, Reekie T, Misagh GH, Narlawar R, Kassiou M, et al. Body temperature and cardiac changes induced by peripherally administered oxytocin, vasopressin and the non-peptide oxytocin receptor agonist WAY 267,464: a biotelemetry study in rats. Br J Pharmacol. 2014;171:2868-87.

40. Klenerova V, Krejci I, Sida P, Hlinak Z, Hynie S. Oxytocin and carbetocin effects on spontaneous behavior of male rats: modulation by oxytocin receptor antagonists. Neuro Endocrinol Lett. 2009;30:335-42.

41. Manning M, Misicka A, Olma A, Bankowski K, Stoev S, Chini B, et al. Oxytocin and vasopressin agonists and antagonists as research tools and potential therapeutics. J Neuroendocrinol. 2012;24:609-28.

42. Ramos L, Hicks C, Kevin R, Caminer A, Narlawar R, Kassiou M, et al. Acute prosocial effects of oxytocin and vasopressin when given alone or in combination with 3,4-methylenedioxymethamphetamine in rats: involvement of the V1A receptor. Neuropsychopharmacology. 2013;38:2249-59.

43. Smith AL, Freeman SM, Voll RJ, Young LJ, Goodman MM. Carbon-11 N-methyl alkylation of L-368,899 and in vivo PET imaging investigations for neural oxytocin receptors. Bioorg Med Chem Lett. 2013;23:902-6.

44. Boulet NP, Cloutier CJ, Ossenkopp KP, Kavaliers M. Oxytocin, social factors, and the expression of conditioned disgust (anticipatory nausea) in male rats. Behav Pharmacol. 2016;27:718-25.

45. Blitzer DS, Wells TE, Hawley WR. Administration of an oxytocin receptor antagonist attenuates sexual motivation in male rats. Horm Behav. 2017;94: 33-9.

46. Bull EJ, Hutson PH, Fone KC. Reduced social interaction following 3,4-methylenedioxymethamphetamine is not associated with enhanced 5 -HT2C receptor responsivity. Neuropharmacology. 2003;44:439-48.

47. Brenes JC, Lackinger M, Hoglinger GU, Schratt G, Schwarting RK, Wohr M. Differential effects of social and physical environmental enrichment on brain plasticity, cognition, and ultrasonic communication in rats. J Comp Neurol. 2016;524:1586-607.

48. Paxinos G, Watson C. The rat brain in stereotaxis coordinates. New York, NY: Academic Press; 1986.

49. Brudzynski SM. Pharmacology of ultrasonic vocalizations in adult rats: significance, call classification and neural substrate. Curr Neuropharmacol. 2015;13:180-92.

50. Striepens N, Kendrick KM, Hanking V, Landgraf R, Wullner U, Maier W, et al. Elevated cerebrospinal fluid and blood concentrations of oxytocin following its intranasal administration in humans. Sci Rep. 2013;3:3440.

51. Ludwig $M$, Leng $G$. Dendritic peptide release and peptide-dependent behaviours. Nat Rev Neurosci. 2006;7:126-36.

52. Calcagnoli F, Kreutzmann JC, de Boer SF, Althaus M, Koolhaas JM. Acute and repeated intranasal oxytocin administration exerts anti-aggressive and proaffiliative effects in male rats. Psychoneuroendocrinology. 2015;51:112-21.

53. Lukas M, Toth I, Reber SO, Slattery DA, Veenema AH, Neumann ID. The neuropeptide oxytocin facilitates pro-social behavior and prevents social avoidance in rats and mice. Neuropsychopharmacology. 2011;36:2159-68.

54. Witt DM, Winslow JT, Insel TR. Enhanced social interactions in rats following chronic, centrally infused oxytocin. Pharmacol Biochem Behav. 1992;43:855-61.

55. Gibson CM, Penn DL, Smedley KL, Leserman J, Elliott T, Pedersen CA. A pilot sixweek randomized controlled trial of oxytocin on social cognition and social skills in schizophrenia. Schizophr Res. 2014;156:261-5.

56. Kosfeld $M$, Heinrichs $M$, Zak PJ, Fischbacher $U$, Fehr E. Oxytocin increases trust in humans. Nature. 2005;435:673-6.

57. Shin NY, Park HY, Jung WH, Park JW, Yun JY, Jang JH, et al. Effects of oxytocin on neural response to facial expressions in patients with schizophrenia. Neuropsychopharmacology. 2015;40:1919-27.

58. Arletti R, Bertolini A. Oxytocin stimulates lordosis behavior in female rats. Neuropeptides. 1985;6:247-53.

59. lovino M, Giagulli VA, Licchelli B, lovino E, Guastamacchia E, Triggiani V. Synaptic inputs of neural afferent pathways to vasopressin- and oxytocin-secreting neurons of supraoptic and paraventricular hypothalamic nuclei. Endocr Metab Immune Disord Drug Targets. 2016;16:276-87.

60. Falke N. Oxytocin stimulates oxytocin release from isolated nerve terminals of rat neural lobes. Neuropeptides. 1989;14:269-74.

61. Ferris CF, Yee JR, Kenkel WM, Dumais KM, Moore K, Veenema AH, et al. Distinct BOLD activation profiles following central and peripheral oxytocin administration in awake rats. Front Behav Neurosci. 2015;9:245. 
62. Neumann ID, Maloumby R, Beiderbeck DI, Lukas M, Landgraf R. Increased brain and plasma oxytocin after nasal and peripheral administration in rats and mice. Psychoneuroendocrinology. 2013;38:1985-93.

63. Boccia ML, Goursaud AP, Bachevalier J, Anderson KD, Pedersen CA. Peripherally administered non-peptide oxytocin antagonist, L368,899, accumulates in limbic brain areas: a new pharmacological tool for the study of social motivation in nonhuman primates. Horm Behav. 2007;52:344-51.

64. Romero-Fernandez W, Borroto-Escuela DO, Agnati LF, Fuxe K. Evidence for the existence of dopamine D2-oxytocin receptor heteromers in the ventral and dorsal striatum with facilitatory receptor-receptor interactions. Mol Psychiatry. 2013:18:849-50.

65. Carson DS, Cornish JL, Guastella AJ, Hunt GE, McGregor IS. Oxytocin decreases methamphetamine self-administration, methamphetamine hyperactivity, and relapse to methamphetamine-seeking behaviour in rats. Neuropharmacology. 2010;58:38-43.

66. Carson DS, Hunt GE, Guastella AJ, Barber L, Cornish JL, Arnold JC, et al. Systemically administered oxytocin decreases methamphetamine activation of the subthalamic nucleus and accumbens core and stimulates oxytocinergic neurons in the hypothalamus. Addict Biol. 2010;15:448-63.

67. Kovacs GL, Sarnyai Z, Barbarczi E, Szabo G, Telegdy G. The role of oxytocindopamine interactions in cocaine-induced locomotor hyperactivity. Neuropharmacology. 1990;29:365-8.

68. Qi J, Yang JY, Song M, Li Y, Wang F, Wu CF. Inhibition by oxytocin of methamphetamine-induced hyperactivity related to dopamine turnover in the mesolimbic region in mice. Naunyn Schmiede Arch Pharmacol. 2008;376: 441-8.

69. Brannan T, Martinez-Tica J, Yahr MD. Changes in body temperature markedly affect striatal dopamine release and metabolism: an in vivo study. J Neural Transm Gen Sect. 1992;89:193-6.

70. Takahata R, Moghaddam B. Activation of glutamate neurotransmission in the prefrontal cortex sustains the motoric and dopaminergic effects of phencyclidine. Neuropsychopharmacology. 2003;28:1117-24.

71. Del Arco A, Segovia G, Mora F. Blockade of NMDA receptors in the prefrontal cortex increases dopamine and acetylcholine release in the nucleus accumbens and motor activity. Psychopharmacol (Berl). 2008;201:325-38.

72. Qi J, Han WY, Yang JY, Wang LH, Dong YX, Wang F, et al. Oxytocin regulates changes of extracellular glutamate and GABA levels induced by methamphetamine in the mouse brain. Addict Biol. 2012;17:758-69.

73. Peris J, MacFadyen K, Smith JA, de Kloet AD, Wang L, Krause EG. Oxytocin receptors are expressed on dopamine and glutamate neurons in the mouse ventral tegmental area that project to nucleus accumbens and other mesolimbic targets. J Comp Neurol. 2017;525:1094-108.

74. Caldwell HK, Stephens SL, Young WS 3rd. Oxytocin as a natural antipsychotic: a study using oxytocin knockout mice. Mol Psychiatry. 2009;14:190-6.
75. Uvnas-Moberg K, Hillegaart V, Alster P, Ahlenius S. Effects of 5-HT agonists, selective for different receptor subtypes, on oxytocin, CCK, gastrin and somatostatin plasma levels in the rat. Neuropharmacology. 1996;35:1635-40.

76. Emiliano AB, Cruz T, Pannoni V, Fudge JL. The interface of oxytocin-labeled cells and serotonin transporter-containing fibers in the primate hypothalamus: a substrate for SSRIs therapeutic effects? Neuropsychopharmacology. 2007;32:977-88.

77. Arakawa $\mathrm{H}$. Involvement of serotonin and oxytocin in neural mechanism regulating amicable social signal in male mice: Implication for impaired recognition of amicable cues in BALB/C strain. Behav Neurosci. 2017;131:176-91.

78. Thompson MR, Callaghan PD, Hunt GE, Cornish JL, McGregor IS. A role for oxytocin and $5-\mathrm{HT}(1 \mathrm{~A})$ receptors in the prosocial effects of 3,4 methylenedioxymethamphetamine ("ecstasy. Neuroscience. 2007;146:509-14.

79. Bowen MT, Carson DS, Spiro A, Arnold JC, McGregor IS. Adolescent oxytocin exposure causes persistent reductions in anxiety and alcohol consumption and enhances sociability in rats. PLoS ONE. 2011;6:e27237.

80. Huang $H$, Michetti C, Busnelli M, Manago F, Sannino S, Scheggia D, et al. Chronic and acute intranasal oxytocin produce divergent social effects in mice. Neuropsychopharmacology. 2014;39:1102-14.

81. Lee PR, Brady DL, Shapiro RA, Dorsa DM, Koenig Jl. Social interaction deficits caused by chronic phencyclidine administration are reversed by oxytocin. Neuropsychopharmacology. 2005;30:1883-94.

82. Song Z, McCann KE, McNeill JKt, Larkin TE 2nd, Huhman KL, Albers HE. Oxytocin induces social communication by activating arginine-vasopressin $\mathrm{V} 1$ a receptors and not oxytocin receptors. Psychoneuroendocrinology. 2014;50:14-9.

83. Suraev AS, Bowen MT, Ali SO, Hicks C, Ramos L, McGregor IS. Adolescent exposure to oxytocin, but not the selective oxytocin receptor agonist TGOT, increases social behavior and plasma oxytocin in adulthood. Horm Behav. 2014;65:488-96.

84. Hung LW, Neuner S, Polepalli JS, Beier KT, Wright M, Walsh JJ, et al. Gating of social reward by oxytocin in the ventral tegmental area. Science. 2017; 357:1406-11.

85. Baracz SJ, Cornish JL. The neurocircuitry involved in oxytocin modulation of methamphetamine addiction. Front Neuroendocrinol. 2016;43:1-18.

86. Lukas M, Wohr M. Endogenous vasopressin, innate anxiety, and the emission of pro-social $50-\mathrm{kHz}$ ultrasonic vocalizations during social play behavior in juvenile rats. Psychoneuroendocrinology. 2015;56:35-44.

87. Seffer D, Rippberger H, Schwarting RK, Wohr M. Pro-social 50-kHz ultrasonic communication in rats: post-weaning but not post-adolescent social isolation leads to social impairments-phenotypic rescue by re-socialization. Front Behav Neurosci. 2015;9:102.

88. Burgdorf J, Wood PL, Kroes RA, Moskal JR, Panksepp J. Neurobiology of 50-kHz ultrasonic vocalizations in rats: electrode mapping, lesion, and pharmacology studies. Behav Brain Res. 2007;182:274-83.

89. Klein BY, Tamir H, Welch MG. PI3K/Akt responses to oxytocin stimulation in Caco2BB gut cells. J Cell Biochem. 2011;112:3216-26. 